\title{
PERANCANGAN FASILITAS EDUPLAY TOYS BERBASIS BUDAYA LOKAL
}

\author{
Maria Yovita, Helena Robertha, Audrey Olivia \\ (Email: myovita2708@gmail.com) \\ Desain Interior \\ Fakultas Seni dan Desain \\ Universitas Kristen Petra Surabaya \\ Jl. Siwalankerto No. 121-131, Surabaya, Indonesia
}

\begin{abstract}
ABSTRAK
Kereta api menjadi salah satu pilihan transportasi yang paling banyak digunakan oleh masyarakat di Indonesia. Tentu saja hal ini berpengaruh terhadap kualitas kenyamanan pada ruang tunggu di stasiun. Beberapa faktor penyebab menurunnya kualitas kenyamanan pada ruang tunggu di stasiun adalah sirkulasi ruang yang berkurang dan polusi suara yang meningkat. Salah satu sumber penyebab meningkatnya polusi suara adalah anak-anak. Untuk meminimalisir polusi suara yang dihasilkan oleh anak-anak, maka diperlukan sebuah fasilitas yang mampu menarik perhatian anak-anak. Oleh karena itu di rancanglah fasilitas Eduplay Toys. Metode yang digunakan dalam proses perancangan Eduplay Toys adalah metode Design Thinking dimana memiliki lima tahapan yaitu tahap Empathize, Define, Ideate, Prototype dan Test. Hasil dari penerapan Eduplay Toys ini selain dapat meminimalisir polusi suara yang dihasilkan oleh anak-anak, dapat digunakan sebagai media untuk memberikan pembelajaran tentang budaya dan pariwisata di Indonesia kepada anak-anak.
\end{abstract}

Kata kunci: anak; budaya; design thinking; bermain; belajar

\section{ABSTRACT}

The train is one of the most widely used transportation options by people in Indonesia. Of course, this affects the quality of comfort in the waiting room at the station. Some of the factors causing the decreasing quality of comfort in waiting rooms at stations are reduced space circulation and increased noise pollution. One source of the causes of increased noise pollution are children. To minimize the noise pollution produced by children, we need a facility that can attract the attention of children. Therefore, the Eduplay Toys facility was designed. The method used in the design process of Eduplay Toys is the Design Thinking method which has five stages namely the Empathize, Define, Ideate, Prototype, and Test stages. The results of the application of Eduplay Toys besides being able to minimize the noise pollution produced by children can be used as a medium to provide learning about culture and tourism in Indonesia to children.

Keywords: children; culture; design thinking; played; study 


\section{PENDAHULUAN}

Area tunggu di stasiun kereta api adalah salah satu fasilitas untuk menunggu yang paling sering digunakan oleh orang-orang dari segala usia. Sembari menunggu transportasi datang, biasanya disediakan beberapa fasilitas agar penumpang merasa nyaman dan dapat mengurangi bosan pada saat menunggu. Diketahui keadaan di stasiun biasanya tergolong ramai dan banyak orang, salah satu contohnya adalah Stasiun Gubeng Baru Surabaya. Penumpang yang datang tidak hanya orang dewasa saja, namun juga anak-anak. Tak jarang terlihat anak-anak berkeliaran sembari menunggu kedatangan kereta api. Rasa bosan anakanak membuatnya berkeliaran dan juga berteriak, menggerutu pada orang tua. Untuk meredam tingkah laku anak-anak tersebut, terkadang orang tua memilih cara praktis dengan memberi gadget, namun gadget memiliki dampak yang buruk bagi anak-anak. Biasanya, anak-anak menggunakan gadget untuk bermain game. Bermain game dapat menimbulkan efek candu yang menyebabkan anak enggan untuk lepas dari gadget. Padahal penggunaan gadget pada anak-anak memiliki jangka penggunaan yang berbeda di setiap usianya. Akademi Dokter Anak Amerika dan Perhimpunan Dokter Anak Kanada menegaskan, anak umur 0-2 tahun tidak boleh terpapar oleh gadget sama sekali. Anak umur 3-5 tahun dibatasi menggunakan gadget hanya satu jam per hari. Dan anak umur 6-18 tahun dibatasi 2 jam saja perhari. Anak-anak dan remaja yang menggunakan gadget melebihi batas waktu yang dianjurkan, memiliki risiko kesehatan serius yang bisa mematikan.

Upaya untuk mengatasi hal tersebut dengan menyediakan fasilitas yang yang dapat mengalihkan perhatian anak-anak pada saat menunggu. Fasilitas tersebut dapat berupa permainan anak-anak. Anak-anak selalu senang bila melakukan kegiatan dalam bentuk permainan. Pada saat bermain akan melatih berbagai macam keahlian dan konsep yang berbeda, bahkan konsep yang belum dia dapatkan sebelumnya. (Sugianto, 1995). Permainan yang dibuat ini terinspirasi dari mainan yang telah diproduksi oleh CV. Omocha Toys yang beralamatkan di Graha Mainan Omocha Toys, Jalan KH Abdullah Bin Nuh no 100 Sindangbarang, Bogor Barat. Cara memainkan permainan ini dengan menggerakkan pion menuju keterangan yang benar. Dengan bermain anak-anak secara tidak langsung dapat mengembangkan kemampuan dari segi aspek sosial, kreativitas, serta mengasah kemampuan berpikir anak serta kemampuan berkomunikasi. Melalui bermain anak akan memahami keterkaitan antara dirinya dan juga lingkungan sosialnya (Rohmah, 2016). 
Melalui permainan ini, selain memiliki tujuan untuk menciptakan suasana yang kondusif, permainan ini juga memiliki manfaat utama untuk menambahan wawasan mengenai kebudayaan daerah dan pariwisata pada anak usia dini. Oleh karenanya desain mainan yang diaplikasikan ini sedikit berbeda, yaitu dengan memasukan budaya yang ada di Indonesia dalam bentuk Candi yang ada di Indonesia.

Desain dari Eduplay Toys ini dirancang untuk anak-anak usia 3-12 tahun, dilengkapi dengan meja yang disesuaikan dengan umur anak-anak. Ketiga meja tersebut memiliki warna yang berbeda-beda. Warna-warna tersebut adalah warna merah, kuning, dan hijau. Warna tersebut dipilih karena dapat menarik perhatian anak agar anak-anak tertarik untuk memainkannya. Pada bagian atas meja terdapat gambar peta yang berfungsi sebagai informasi daerah. Bentuk dari meja tersebut dibuat menyerupai labirin agar anak-anak dapat menggerakkannya. Terdapat dua kursi pada tiap meja untuk anak-anak yang ingin duduk dan bermain.

Lokasi pengamatan yang dipilih adalah di Stasiun Gubeng Baru Surabaya. Alasanya karena banyak masyarakat saat ini yang menggunakan fasilitas transportasi kereta api. Selain itu, pada bagian ruang tunggu ada yang bersifat umum dan khusus (untuk penumpang). Hal inilah yang memudahkan kami untuk melakukan observasi lapangan.

\section{METODE PENELITIAN}

Pada perancangan ini, metode yang digunakan adalah metode Design Thinking. Tahaptahap yang terdapat dalam metode ini adalah Empathize, Define, Ideate, Prototype, dan Test.

\section{Tahap Empathize}

Tahap Empathize merupakan tahap awal mendalami permasalahan yang ada dan mengumpulkan data dengan melakukan eksplorasi literatur, analisa lapangan di Stasiun Gubeng Baru Surabaya. Hasil eksplorasi yang didapatkan berupa :

- Model permainan yang dapat menambah perkembangan anak-anak

- Perkembangan anak-anak

- Sifat-sifat anak

- Dimensi tubuh

- Fungsi utama permainan

- Finishing yang aman bagi anak-anak 
- Kebiasaan anak-anak yang menunggu di Stasiun Gubeng Surabaya

- Kenyamanan pengunjung terhadap tingkah laku anak-anak di Stasiun Gubeng Surabaya

- Desain fasilitas bermain anak yang mampu memberikan edukasi

\section{Tahap Define}

Tahap Define merupakan tahap mengumpulkan, menganalisa data-data dan menentukan hal-hal apa saja yang perlu dikembangkan ke tahap selanjutnya.

- Tidak semua ruang tunggu menyediakan fasilitas khusus untuk anak-anak

- Dibutuhkan fasilitas eduplay toys bagi anak-anak yang mampu menarik perhatian anakanak untuk memainkan

- Dibutuhkan fasilitas eduplay toys bagi anak-anak yang tidak hanya menarik tapi juga mengedukasi anak-anak.

- Dibutuhkan fasilitas eduplay toys bagi anak-anak dengan karakteristik dan standarisasi dari pemerintah.

\section{Jenis - jenis permainan}

Mildred Parten melakukan studi klasik terhadap aktivitas permainan anak-anak prasekolah. berdasarkan observasinya terhadap anak usia 2 hingga 5 tahun, Parten menemukan 6 kategori permainan (Parten,1932):

\section{- Permainan Unoccupied}

Anak dapat melihat sesuatu yang menarik dan memperagakannya dengan gerakan gerakan yang tidak terkontrol.

- Permainan Solitary

Anak dalam sebuah kelompok asyik bermain sendiri-sendiri dengan berbagai macam alat permainan, sehingga menimbulkan rasa ketidak pedulian terhadap apapun yang terjadi.

- Permainan Onlooker

Anak yang melihat temannya yang lain bermain. Anak tersebut ikut berbicara dan mulai berinteraksi dengan teman-teman yang lainnya dengan mengajukan pertanyaanpertanyaan, tetapi la tidak terlibat dalam aktivitas permainan tersebut.

- Permainan Parallel

Anak bermain dengan alat permainan yang sama, tetapi tidak terjadi kontak antara satu dengan yang lainnya. Bisa juga anak-anak saling bertukar alat permainan. 


\section{- Permainan Associative}

Anak-anak bermain bersama dan saling meminjam alat, tetapi tidak mengarah pada satu tujuan yang sama. Pada permainan ini tidak ada pembagian peranan dan pembagian alat-alat permainan.

- Permainan Cooperative.

Anak-anak yang bermain dengan dipimpin dan di arahkan oleh satu atau dua orang anak. Biasanya kelompok bermain ini melakukan kegiatan-kegiatan konstruktif dan membuat sesuatu yang nyata, dimana setiap anak memiliki peran sendiri-sendiri

\section{Tahap Ideate}

Tahap Ideate merupakan tahap mengemukakan ide desain sebagai solusi atas masalah yang ada, dengan membuat konsep dan transformasi desain.

\section{a. Brainstorming ldeas}

Tahap dimana mengumpulkan semua ide-ide berdasarkan hasil tahap define. Ide-ide yang muncul kemudian dipadukan dan digunakan sebagai pengembangan desain akhir. Ide-ide yang dikumpulkan adalah sebagai berikut:

○ Menggunakan finishing warna merah, biru, hijau, kuning.

○ Ukuran untuk meja adalah A (98 cm x $49 \mathrm{~cm} \times 49 \mathrm{~cm}) ; B(112 \mathrm{~cm} \times 56 \mathrm{~cm} \times 56,5 \mathrm{~cm})$; C (126 cm x $63 \mathrm{~cm} \times 63,5 \mathrm{~cm})$ dengan persyaratan mampu dimainkan dengan nyaman, sesuai dengan anthropometry anak.

- Mudah dioperasikan dengan menggunakan tangan.

○ Desain visual yang menarik anak-anak melalui warna dan objek.

b. Sketsa Manual

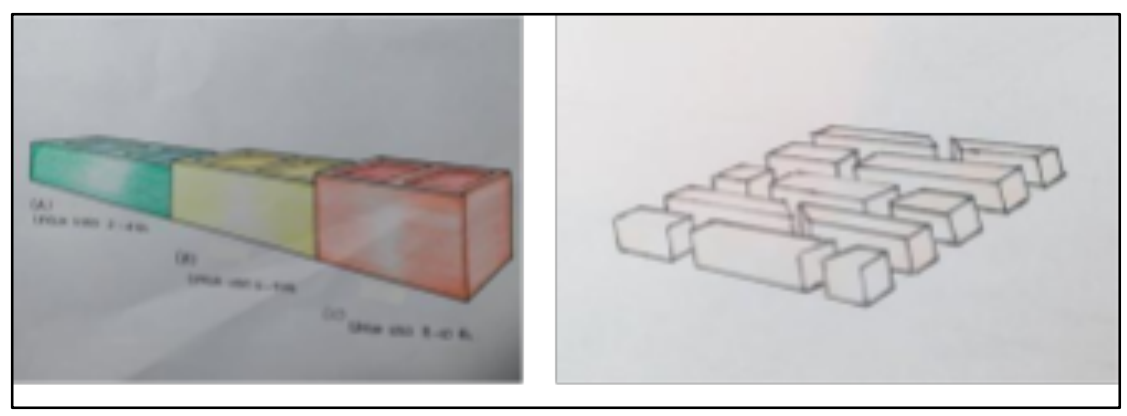

Gambar 1. Sketsa Eduplay Toys Sumber: Dokumentasi Pribadi 


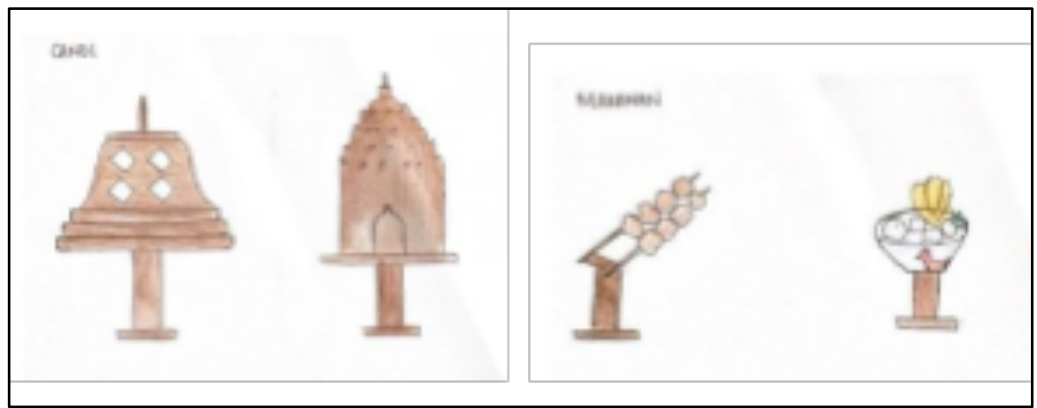

Gambar 2. Sketsa pion

Sumber: Dokumentasi Pribadi

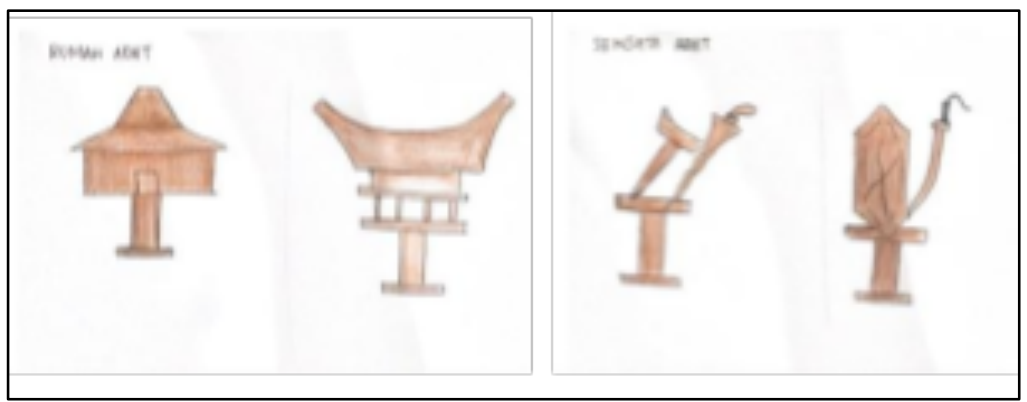

Gambar 3. Sketsa pion

Sumber: Dokumentasi Pribadi

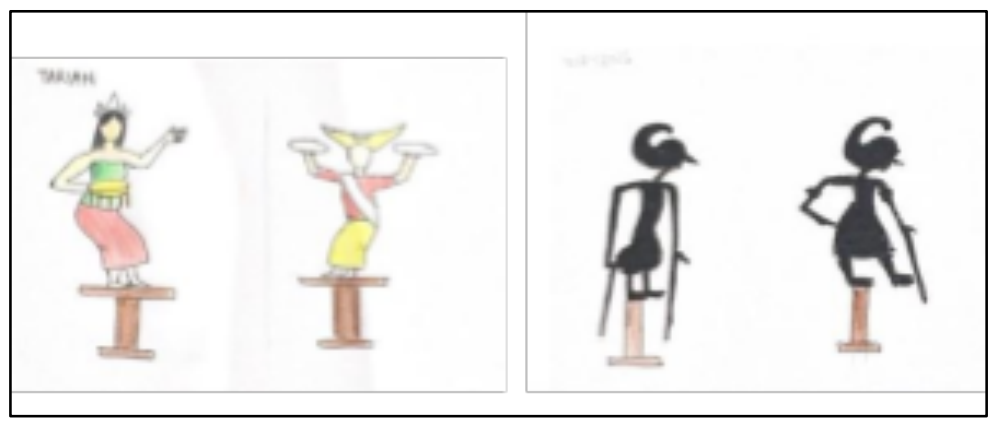

Gambar 4. Sketsa pion

Sumber: Dokumentasi Pribadi

\section{c. Prototype}

Tahap prototype merupakan tahap pengembangan desain sebagai solusi dari permasalahan guna memperjelas bentukan visual dari desain akhir, Hasil yang diperoleh adalah 3D modeling menggunakan software. Pada tahap ini perancangan objek diawali dengan membuat ukuran sebenarnya pada aplikasi SketchUp dan membuat gambar tampak meja dengan skala 1:10 dan pion dengan skala sebenarnya (1:1). Material yang digunakan untuk perabot ini adalah multiplex karena tidak terlalu berat, mudah didapatkan, dan diolah. 
Serat Rupa Journal of Design, January 2020, Vol.4, No.1: 26-39

E-ISSN: 2477-586X, ISSN: 2338-3348 | https://doi.org/10.28932/srjd.v4i1.1931 | Received: 29-09-2019, Accepted: 16 -01-2020

Maria Yovita, Helena Robertha, Audrey Olivia

Perancangan Fasilitas Eduplay Toys Berbasis Budaya Lokal

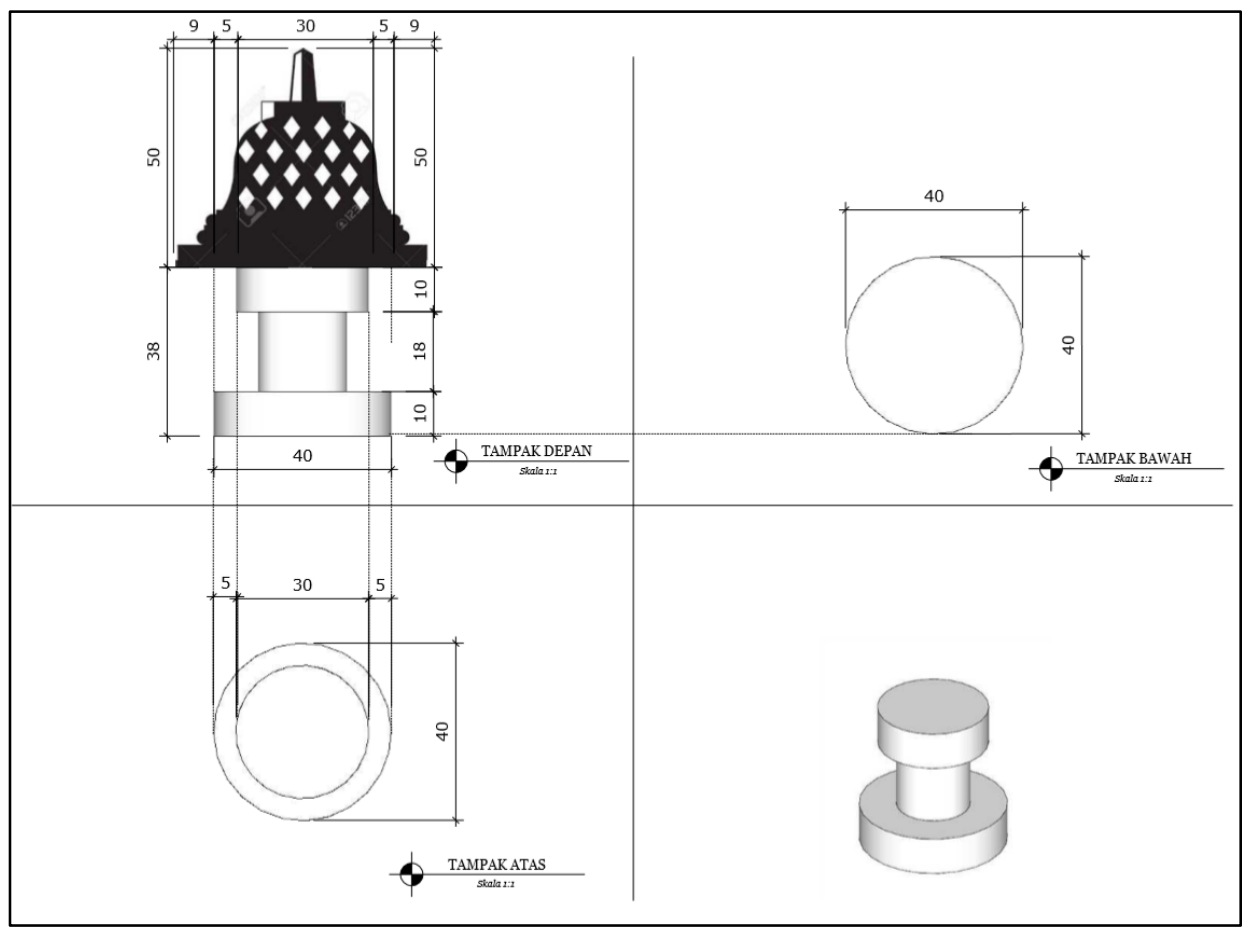

Gambar 5. Gambar teknik pion skala 1:1

Sumber: Dokumentasi Pribadi 2019

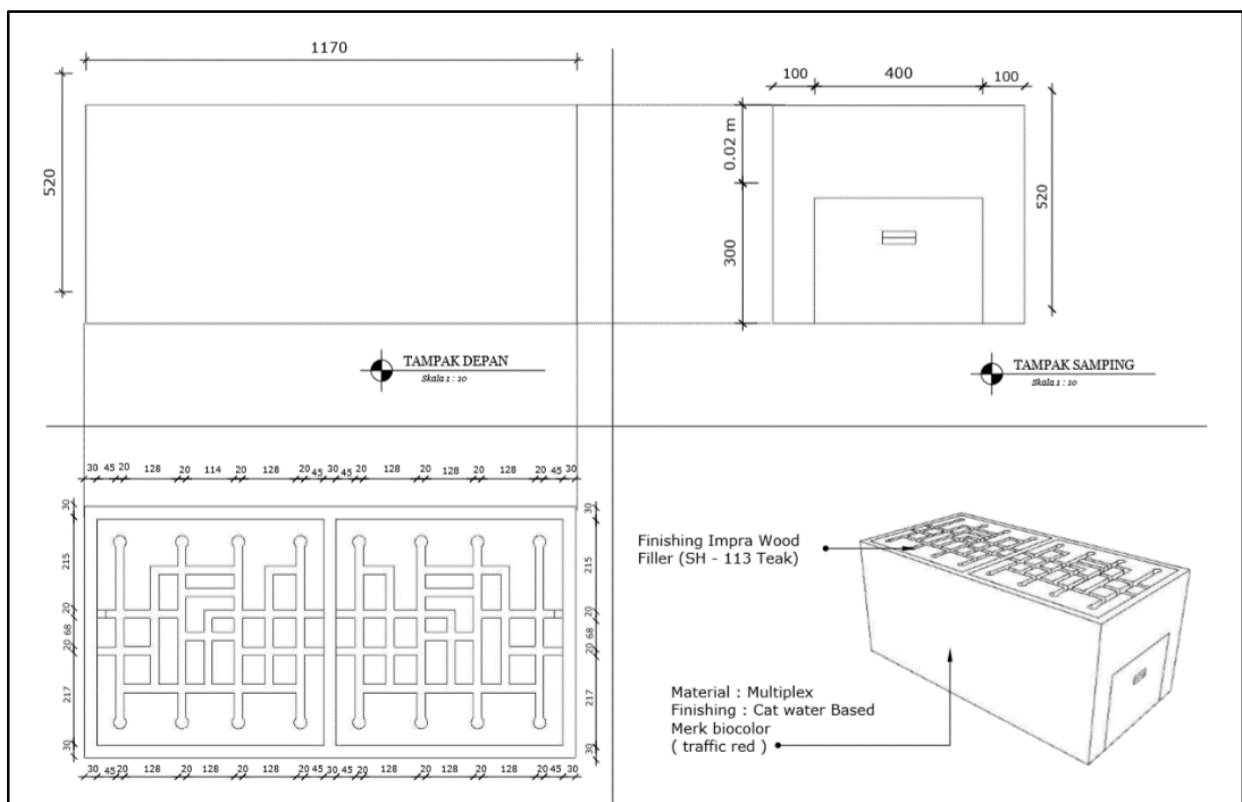

Gambar 6. Gambar teknik meja dan kursi (skala 1:10) Sumber: Dokumentasi pribadi 2019 
Serat Rupa Journal of Design, January 2020, Vol.4, No.1: 26-39

E-ISSN: 2477-586X, ISSN: 2338-3348 | https://doi.org/10.28932/srjd.v4i1.1931 | Received: 29-09-2019, Accepted: 16 -01-2020 Maria Yovita, Helena Robertha, Audrey Olivia

Perancangan Fasilitas Eduplay Toys Berbasis Budaya Lokal

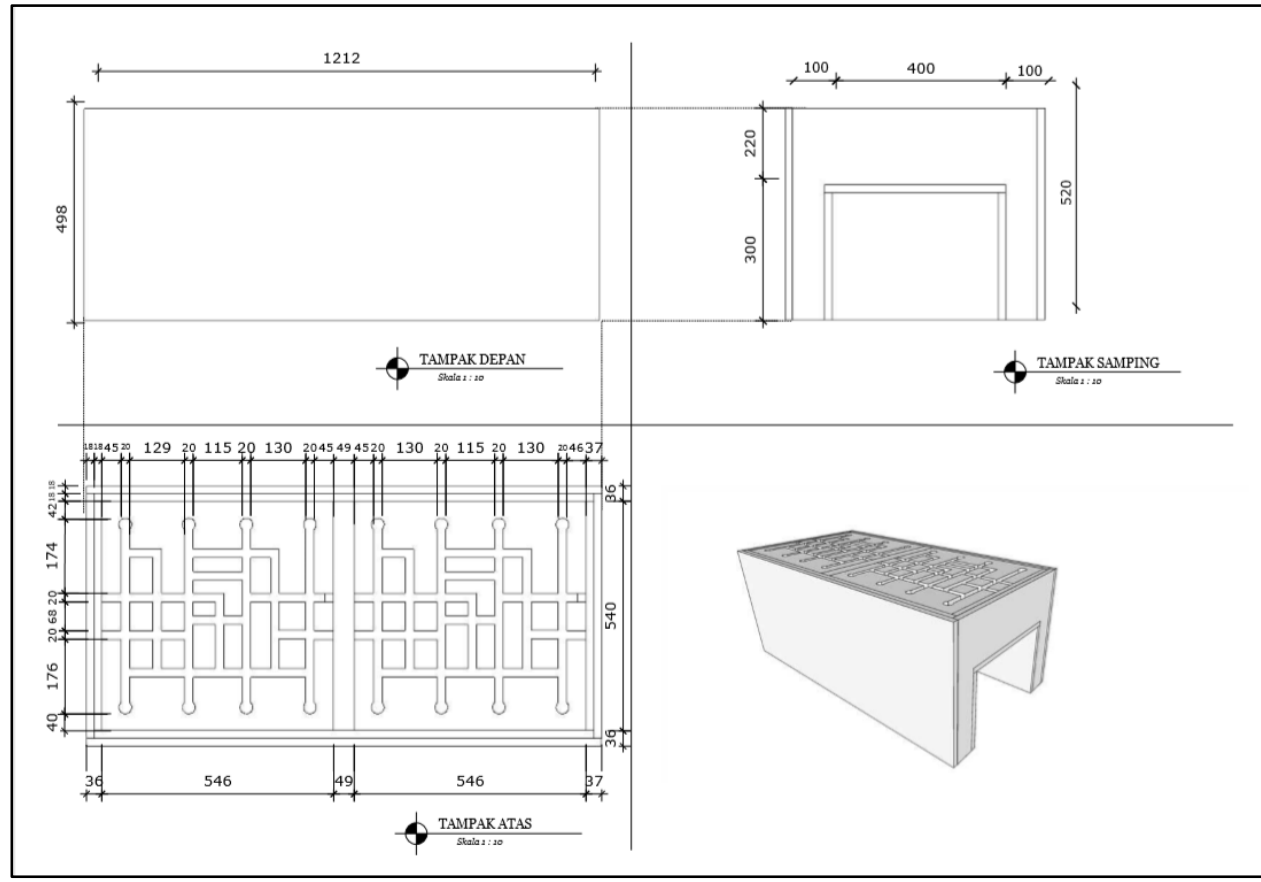

Gambar 7. Gambar teknik meja (skala 1:10)

Sumber: Dokumentasi Pribadi 2019

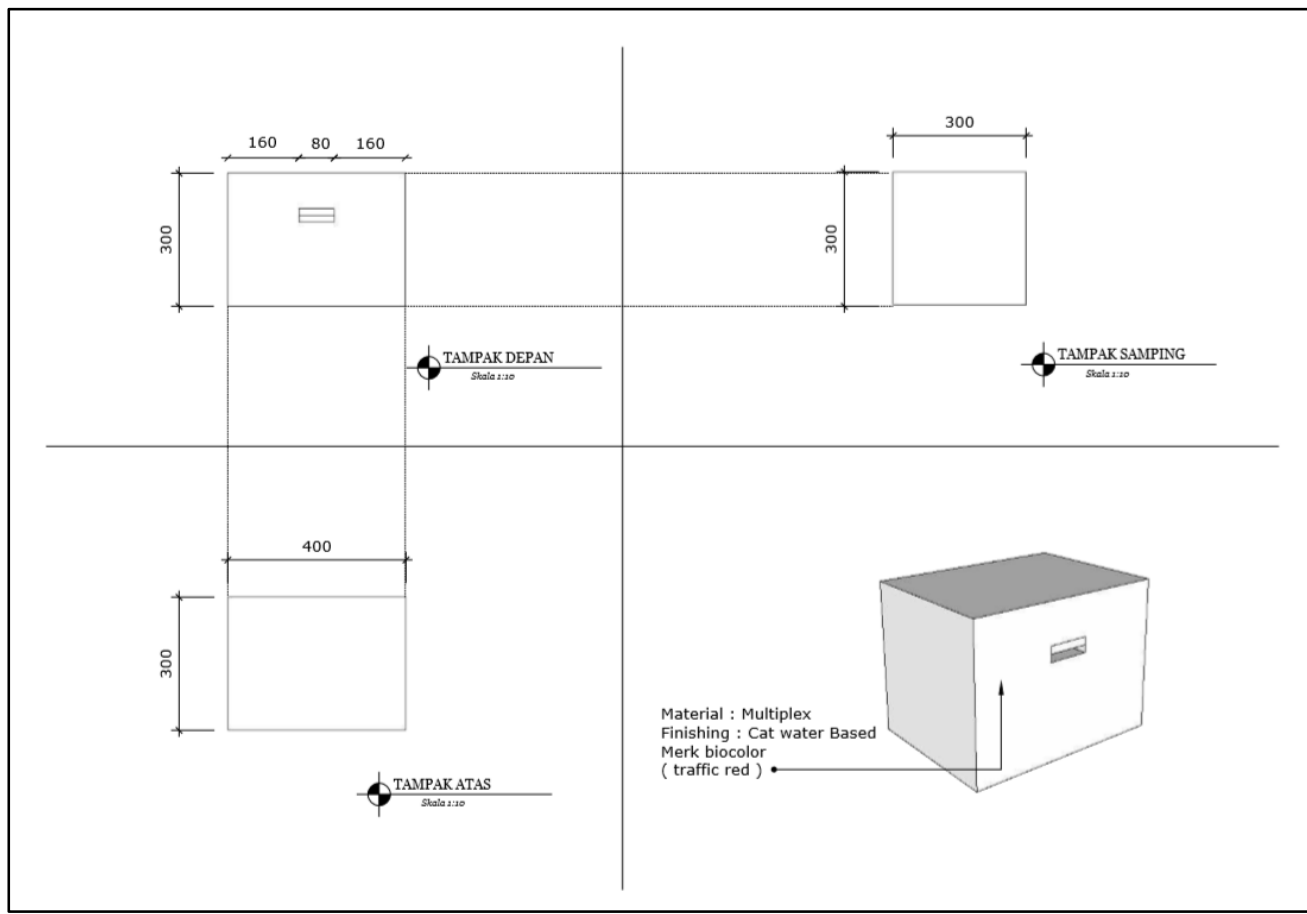

Gambar 8. Gambar teknik kursi (skala 1:10)

Sumber: Dokumentasi Pribadi 2019 


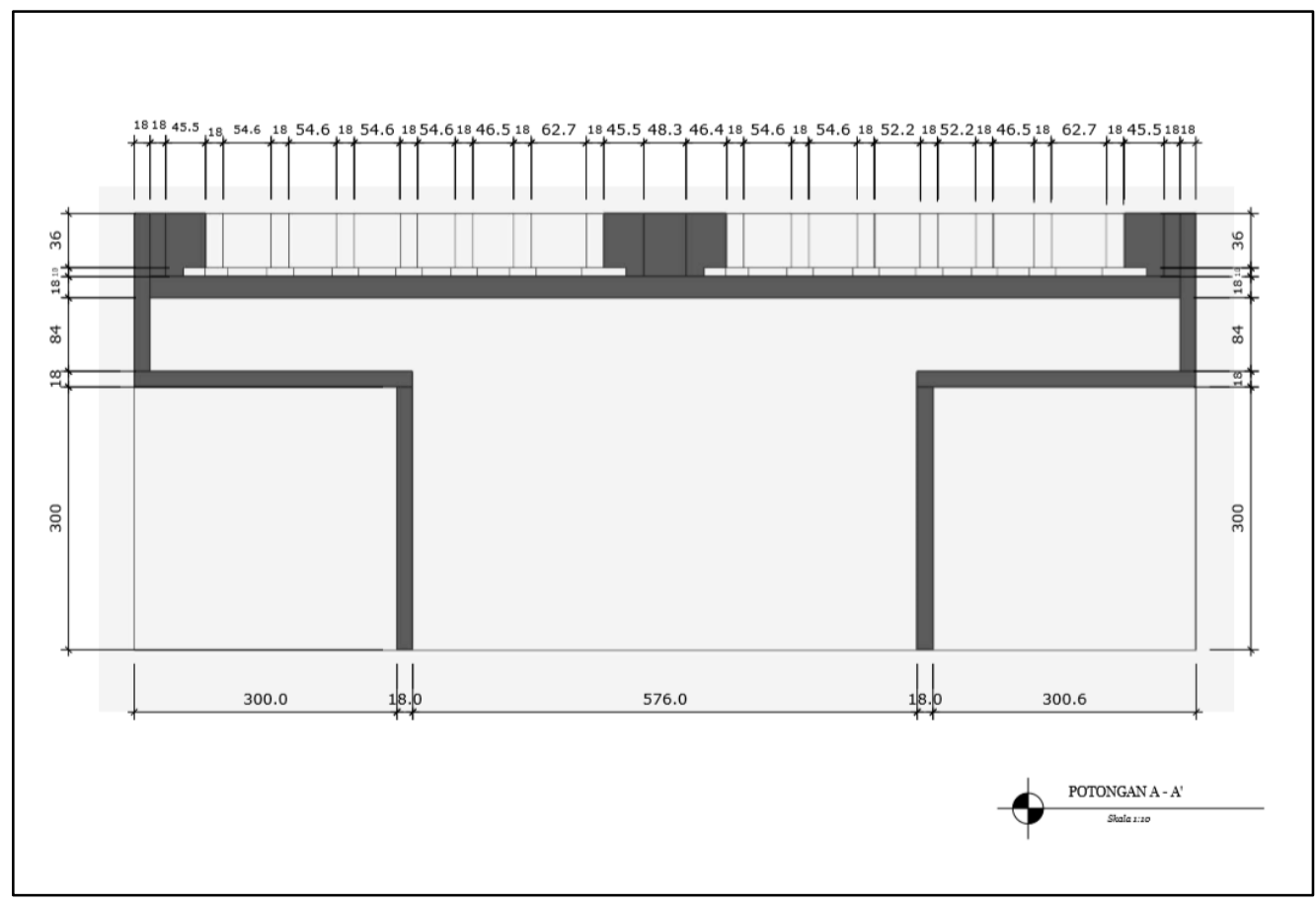

Gambar 9. Gambar potongan (skala 1:10)

Sumber : Dokumentasi Pribadi

\section{d. Test / Desain Akhir}

Tahap Test merupakan tahapan akhir dari metode design thinking, yaitu tahapan uji desain, dan tahapan pertanggungjawaban hasil desain. Melalui tahapan ini juga, didapatkan final design yang menjadi desain akhir dalam perancangan. Dalam tahap ini meja sudah harus sudah siap untuk digunakan.

Bahan utama yang digunakan dalam pembuatan fasilitas eduplay toys ini adalah plywood dengan ketebalan $18 \mathrm{~mm}$. Konstruksi yang digunakan ialah sekrup. Finishing dari meja dan kursi menggunakan cat yang water based sehingga aman untuk anak-anak karena mengandung bahan yang tidak menimbulkan bau yang menyengat. Selain aman bagi anak-anak penggunaan cat water based juga ramah lingkungan sehingga produk ini dapat digunakan di berbagai jenis ruangan dan tempat umum selain stasiun. 
Serat Rupa Journal of Design, January 2020, Vol.4, No.1: 26-39

E-ISSN: 2477-586X, ISSN: 2338-3348 | https://doi.org/10.28932/srjd.v4i1.1931 | Received: 29-09-2019, Accepted: 16 -01-2020 Maria Yovita, Helena Robertha, Audrey Olivia

Perancangan Fasilitas Eduplay Toys Berbasis Budaya Lokal

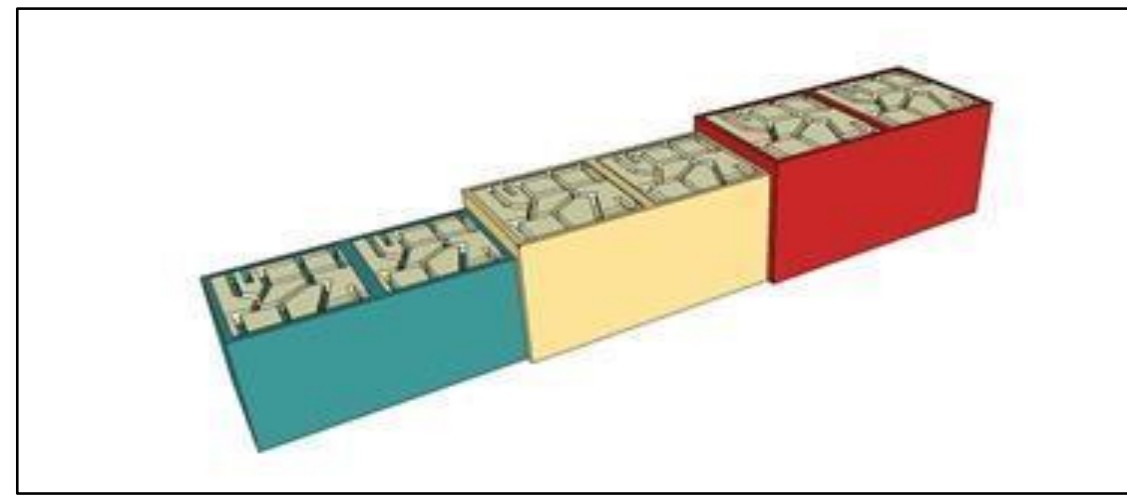

Gambar 10. Perspektif desain eduplay toys Sumber: Dokumentasi Pribadi

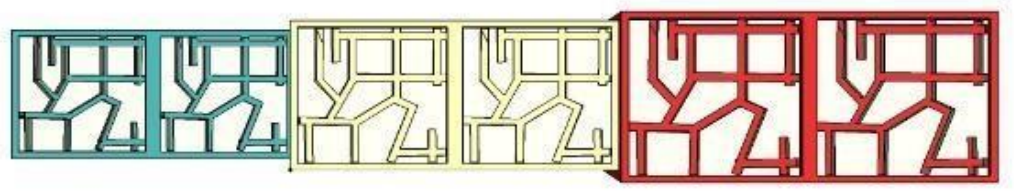

Gambar 11. Tampak atas desain eduplay toys Sumber: Dokumentasi Pribadi

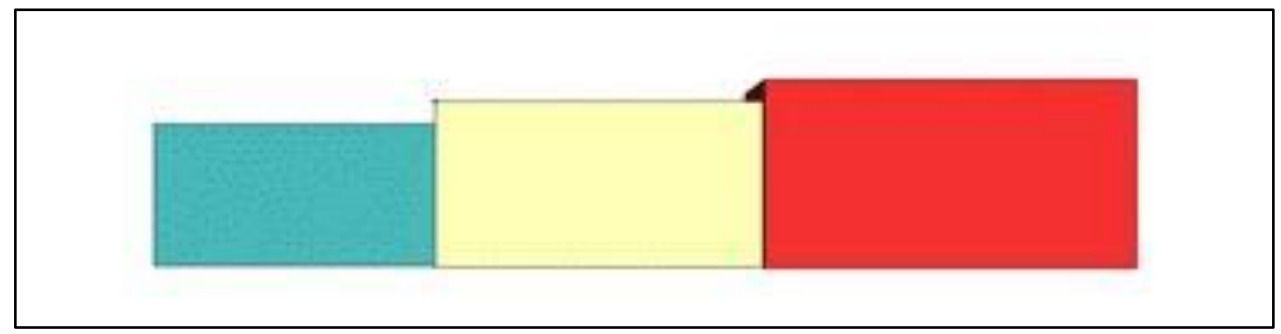

Gambar 12. Tampak samping desain eduplay toys Sumber: Dokumentasi Pribadi

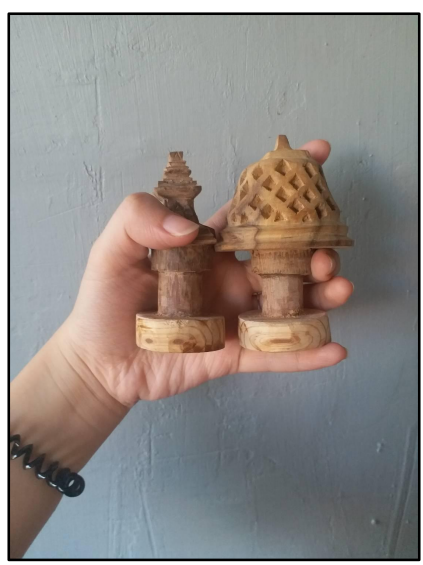

Gambar 13. Pion Candi Sumber: Dokumentasi Pribadi 


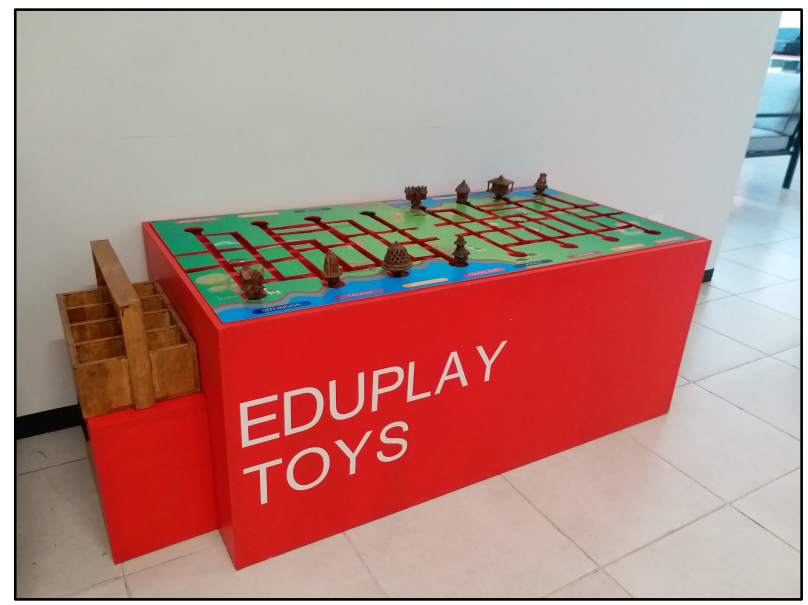

Gambar 14. Meja eduplay toys Sumber: Dokumentasi Pribadi

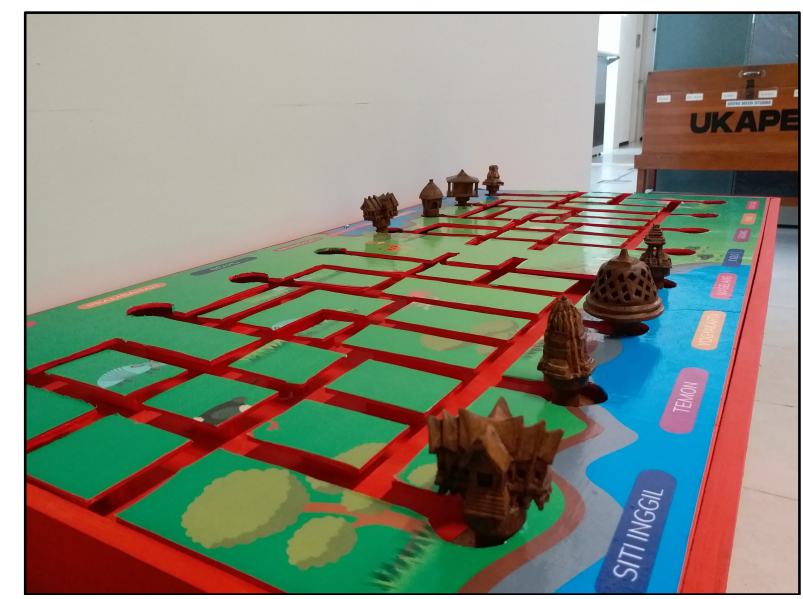

Gambar 15. Meja eduplay toys dengan keterangan penjelasan Sumber: Dokumentasi Pribadi

\section{PEMBAHASAN}

Lokasi yang dipilih Penulis adalah Stasiun Gubeng Surabaya dan jenis barang yang diletakkan adalah fasilitas meja anak dengan permainan. Penggunaan meja ini memiliki capaian khusus dan potensi yang dapat diberikan kepada anak-anak untuk mencapai keberhasilan dari produk.

\section{Aspek Visual}

Secara visual meja Eduplay Toys sudah sesuai dengan gambar perancangan.

Produk sudah diwarna dengan menggunakan warna cerah seperti merah, kuning, dan hijau tosca untuk menarik mata anak-anak untuk memainkannya.

\section{Aspek Fungsi}

Fungsi dari permainan ini adalah sebagai media belajar dan bermain. Pion di 
meja berbentuk ciri khas budaya daerah. Pion tersebut dapat digerakkan menuju ke satu keterangan daerah. Berdasarkan teori taksonomi Bloom bahwa terdapat tiga model hierarki yang pada dasarnya digunakan untuk mengklasifikasi perkembangan pendidikan anak secara objektif. Tiga model aspek tersebut diantaranya adalah kognitif, afektif dan psikomotorik (Bloom, 1956).

Tabel 1. Keuntungan aspek kognitif, afektif, dan psikomotorik

\begin{tabular}{|c|c|c|c|c|}
\hline Keterangan produk & Kegiatan & Kognitif & Psikomotorik & Afektif \\
\hline $\begin{array}{l}\text { 1. Warna produk } \\
\text { merah, kuning } \\
\text { dan biru dengan } \\
\text { tulisan EDUPLAY } \\
\text { TOYS }\end{array}$ & $\begin{array}{l}\text { Melihat } \\
\text { produk yang } \\
\text { memiliki } \\
\text { warna cerah } \\
\text { dan terang }\end{array}$ & $\begin{array}{l}\text { Anak akan belajar } \\
\text { mengetahui dan } \\
\text { memahami bahwa } \\
\text { produk tersebut } \\
\text { adalah sebuah } \\
\text { permainan dari } \\
\text { kata-kata yang } \\
\text { tertera }\end{array}$ & $\begin{array}{l}\text { Anak akan melakukan } \\
\text { reaksi yang diarahkan } \\
\text { dari melihat sebuah } \\
\text { warna dan tulisan dari } \\
\text { permainan }\end{array}$ & $\begin{array}{l}\text { Anak akan } \\
\text { termotivasi untuk } \\
\text { bertanya dan } \\
\text { memperhatikan } \\
\text { permainan apa itu }\end{array}$ \\
\hline $\begin{array}{l}\text { 2. Stiker dengan } \\
\text { tulisan-tulisan } \\
\text { nama candi, } \\
\text { rumah adat dan } \\
\text { peta }\end{array}$ & $\begin{array}{l}\text { Membaca } \\
\text { tulisan-tulisan } \\
\text { dan } \\
\text { mengamati }\end{array}$ & $\begin{array}{l}\text { Anak belajar } \\
\text { memahami dan } \\
\text { mengetahui jenis- } \\
\text { jenis candi dan dan } \\
\text { kotanya }\end{array}$ & $\begin{array}{l}\text { Anak belajar untuk } \\
\text { mencari dan membaca } \\
\text { mana yang paling } \\
\text { tepat }\end{array}$ & $\begin{array}{l}\text { Anak akan tertarik } \\
\text { dan bertanya-tanya } \\
\text { serta mendiskusikan } \\
\text { dengan dirinya } \\
\text { tentang nama-nama } \\
\text { tersebut }\end{array}$ \\
\hline $\begin{array}{l}\text { 3. Labirin dengan } \\
\text { pion berbentuk } \\
\text { candi dan rumah } \\
\text { adat }\end{array}$ & $\begin{array}{l}\text { Menggerakka } \\
\text { n pion ke } \\
\text { tempat yang } \\
\text { sesuai dengan } \\
\text { instruksi }\end{array}$ & $\begin{array}{l}\text { Anak akan } \\
\text { mengenal dan } \\
\text { mengetahui } \\
\text { tentang jenis candi } \\
\text { dan rumah adat, } \\
\text { anak mampu } \\
\text { menemukan dan } \\
\text { memahami } \\
\text { keberagaman } \\
\text { budaya di } \\
\text { Indonesia }\end{array}$ & $\begin{array}{l}\text { Anak akan melakukan } \\
\text { reaksi menggerakkan } \\
\text { dan membuat } \\
\text { pengembangan serta } \\
\text { memecah wawasan } \\
\text { baru }\end{array}$ & $\begin{array}{l}\text { Anak akan } \\
\text { termotivasi, } \\
\text { melakukan, dan } \\
\text { mengidentifikasi, } \\
\text { memilih, pion-pion } \\
\text { ke tempat yang } \\
\text { benar. Anak akan } \\
\text { belajar untuk lebih } \\
\text { menghargai } \\
\text { kebudayaan } \\
\text { Indonesia. }\end{array}$ \\
\hline
\end{tabular}




\section{Aspek Kognitif}

Aspek kognitif adalah aspek yang berkaitan dengan nalar atau proses berpikir, yaitu kemampuan dan aktivitas otak untuk mengembangkan kemampuan secara rasional.

\section{Aspek Afektif}

Aspek afektif merupakan materi yang berdasarkan segala sesuatu yang berkaitan dengan emosi seperti penghargaan, nilai, perasaan, semangat, minat, dan sikap terhadap sesuatu hal.

\section{Psikomotorik}

Aspek psikomotorik adalah hal yang meliputi perilaku gerakan dan koordinasi jasmani, keterampilan motorik dan kemampuan fisik seseorang. Keterampilan yang akan berkembang jika sering dipraktekkan ini dapat diukur berdasarkan jarak, kecepatan, kecepatan, teknik dan cara pelaksanaan.

\section{Potensi Khusus}

Perancangan produk Eduplay Toys diharapkan dapat menambah wawasan anakanak mengenai budaya daerah. Banyak anak yang kurang mengerti budaya daerahnya, yang berkaitan dengan rumah adat, pakaian adat, senjata, makanan daerah, dan sebagainya. Selain itu, anak-anak juga dapat bermain bersama di tempat umum seperti Stasiun Gubeng. Dengan menggerakkan pion ke titik yang sudah ditentukan (melalui clue) mereka dapat mengembangkan kemampuan motorik dan kepekaan panca indra. Selain mengembangkan kemampuan yang ada di dalam diri mereka, dengan bermain Eduplay Toys di tempat umum juga dapat mengajak mereka untuk bisa lebih bersosialisasi dengan orang lain. Fasilitas bermain Eduplay Toys ini juga diberikan dengan warna-warna yang menarik sehingga anak-anak lebih tertarik dan bisa memainkannya. 


\section{PENUTUP}

Eduplay toys dirancang untuk anak-anak usia 3-12 tahun yang ikut menunggu di Stasiun Gubeng Surabaya. Selain dirancang untuk bermain, Eduplay toys ini tujuan utamanya dirancang agar anak-anak dapat belajar dan menambah ilmu pengetahuan mengenai kebudayaan dan pariwisata di Indonesia. Secara visual permainan ini bisa mengalihkan perhatian anak dan secara fungsi digunakan sebagai media untuk bermain dan belajar. Permainan ini mengutamakan proses perkembangan anak secara psikomotorik, kognitif, dan afektif. Diharapkan secara kognitif akan mengembangkan proses pengetahuan, pemahaman, dan analisis dari anak. Secara afektif akan memberikan pengembangan dalam hal responsif pada anak dan juga secara psikomotorik memberikan pengembangan motorik yang baik. Dalam merancang eduplay toys tersebut, Penulis menggunakan metode design thinking dengan lima tahapan yaitu empathize, define, ideate, prototype, dan test.

\section{DAFTAR PUSTAKA}

Bloom, Benjamin S., etc. (1956). Taxonomy of Educational Objectives : The Classification of Educational Goals, Handbook I Cognitive Domain. New York : Longmans, Green and Co.

Parten, Mildred. (1932). Stages Of Development Social Play. Diunduh 29 September 2019 dari http://childdevelopmentprograms.ca/

Penelitian:ini 10 Bahaya Gadget bagi Anak di bawah usia 12 Tahun. Diakses pada Januari 03, 2018, dari https://id.theasianparent.com/10-bahayapenggunaan-gadget-pada-anak/

Rohmah, Naili. (2016). Bermain dan Pemanfaatannya Dalam Perkembangan Anak Usia Dini. Jurnal Tarbawi, 13(2), 29-35.

Sugianto, Mayke T.(1995). Bermain, Mainan, dan Permainan. Jakarta: DEPDIKBUD. 